\title{
Effects of Chronic in Utero Hypoxia on the Pulmonary Vasculature of the Newborn Guinea Pig
}

\author{
JOHN D. MURPHY, ${ }^{1}$ MARK J. ARONOVITZ, AND LYNNE M. REID \\ Departments of Pathology and Cardiology, Children's Hospital, Harvard Medical School, Boston, \\ Massachusetts 02115
}

\begin{abstract}
This report analyzes the effect on pulmonary vascular structure and function in the newborn guinea pig of chronic fetal hypoxemia, induced by maternal hypobaric hypoxia (380-420 torr) without direct interference with the utero-placental blood flow. Six pregnant guinea pigs were maintained in hypobaric chambers, 10 newborns from their litters being the hypoxic group. Twenty newborns from the litters of 10 pregnant guinea pigs maintained in air were the control group. After spontaneous delivery catheters were placed in the left carotid and the main pulmonary arteries of the newborns. Oxygen consumption was measured, pressures recorded from the pulmonary artery, right ventricle, and right atrium, oxygen saturation and hemoglobin concentration estimated on blood from systemic arteries, pulmonary artery, and right atrium, and cardiac output calculated (Fick principle). All data were normalized per kilogram body weight. Morphometric analysis of the pulmonary vasculature after injection of the pulmonary arteries showed no difference between the groups. Contrary to expectation chronic hypoxemia in utero did not cause pulmonary hypertension or the precocious muscularization of the precapillary unit found in human cases of persistent pulmonary hypertension: it caused growth retardation, a feature not typical of the human syndrome. (Pediatr Res 20: 292-295, 1986)
\end{abstract}

\section{Abbreviation}

$\dot{\mathrm{V}} \mathrm{O}_{2}$, oxygen consumption

Acute alveolar hypoxia in man and experimental animals causes pulmonary hypertension by vasoconstriction that is rapidly reversible on return to air $(1-5)$. Chronic hypoxia causes progressive hypertension and structural changes in the pulmonary vasculature that are only partly reversible (6-8). Morphometric analysis shows that these changes include an increase in the thickness of the arterial medial coat, the appearance of muscle in the smaller more peripheral arteries that are normally not muscular, and a reduction in the density of intraacinar arteries that fill with injection medium $(6,7)$. In the exteriorized fetal sheep and newborn lamb, numerous studies have demonstrated an increase in pulmonary vascular resistance in response to acute

Received June 13, 1984; accepted November 18, 1985.

Address for correspondence and reprints Dr. Lynne M. Reid, The Children's Hospital, Department of Pathology, 300 Longwood Avenue, Boston, MA 02115.

This work was supported by Grant 23591 from Heart, Lung and Blood Division of the National Institutes of Health.

'Present address Division of Cardiology, Children's Hospital of Philadelphia, 34th St. B Civic Center Boulevard, Philadelphia, PA 19104. hypoxia $(5,9,10)$. The speculation that chronic fetal hypoxemia causes persistent pulmonary hypertension in the newborn is based on these acute studies in which hypoxemia is caused by a reduction in uterine or placental blood flow. Few investigators have examined the effect of chronic hypoxemia on the intact fetus.

Recently we have reported severe structural abnormalities of the microcirculation of the lungs in two series of newborns with fatal persistent pulmonary hypertension $(11,12)$, notably muscularization of the intraacinar pulmonary arteries that normally at this age are free of muscle. Our present study analyzes the effect on the structure and function of the pulmonary vascular bed of the newborn guinea pig after chronic fetal hypoxemia induced by maternal hypoxia without any direct interference with the utero placental blood flow.

\section{MATERIALS AND METHODS}

Sixteen pregnant guinea pigs were used in this experiment: all delivered spontaneously. When thought to be about 3 wk before delivery, an animal was allocated to one of two groups. Ten of the pregnant animals were maintained in ambient air throughout pregnancy. Twenty newborns from the litters were successfully catheterized and were designated the control group. Six pregnant animals were placed in hypobaric chambers in which over 2 days the pressure was reduced to $380-420$ torr (equivalent to $10.5-$ $11.6 \%$ oxygen concentration at sea level): 10 newborns from their litters were the hypoxic group. The pressure was maintained at this level for the rest of gestation (mean 21.5 days, range 1728 days) except for a daily 10 -min period when the guinea pigs were returned to air, examined, and the food and water replenished. After spontaneous delivery the guinea pigs were removed from the hypobaric chamber and the infants remained with the mother until hemodynamic studies were performed. Usually two pups from each litter were studied. The newborn guinea pigs were weighed, given sodium pentobarbital, $10 \mathrm{mg} / \mathrm{kg}$ by intraperitoneal injection, and maintained under a radiant warmer throughout the study.

Under local anesthesia (Lidocaine $0.5 \%$ ) silastic catheters (external diameter $0.56 \mathrm{~mm}$ ) were placed in the left carotid artery and the main pulmonary artery using techniques modified from those developed for catheterization of the adult rat $(7,13)$. Briefly, under direct visualization the right jugular vein is isolated and cannulated with an introducer specially prepared from a blunted no. 18 gauge needle, into which a silastic catheter has been passed. The catheter is connected by a blunted no. 25 gauge needle to a microdisplacement transducer (Ailtech-rated 0.0006 $\mathrm{mm} / 100 \mathrm{~mm} \mathrm{Hg}$ ). The frequency response of this system has been tested and found to be more than adequate to produce excellent recordings of intravascular pressure wave forms in small animals. The introducer with catheter is advanced through the 


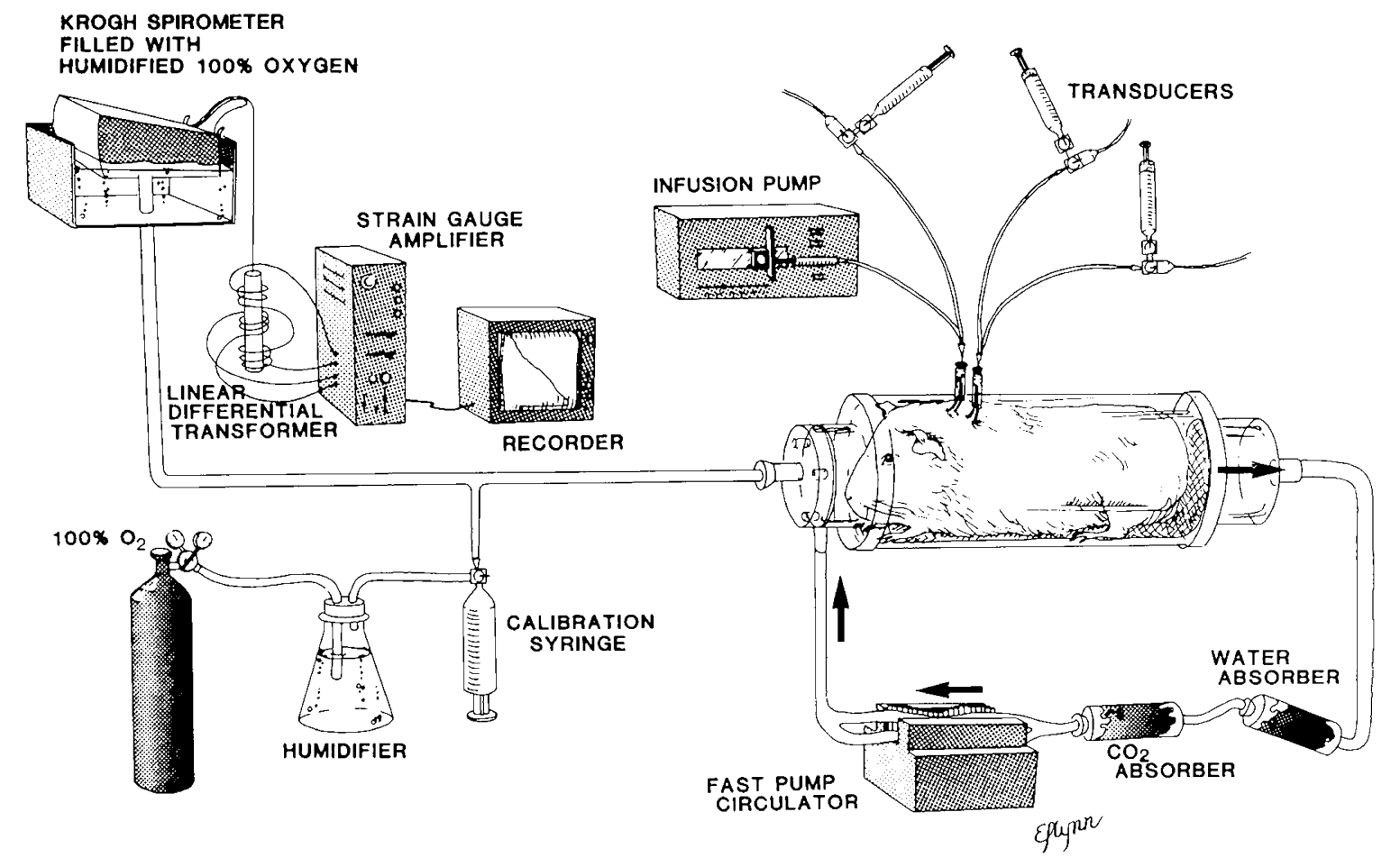

Fig. 1. Diagrammatic representation of apparatus used to determine oxygen consumption (see text).

superior vena cava right atrium and into the right ventricle while monitoring the intravascular pressures. The silastic catheter is then advanced about $1 \mathrm{~cm}$ and with some manipulation the main pulmonary artery is entered. The introducer is withdrawn leaving the catheter in the pulmonary artery. The catheters are secured in place and the newborn animals transferred to a specially designed capsule for the measurement of oxygen consumption while pressure recordings are made from the pulmonary and systemic arteries. $\dot{\mathrm{V}} \mathrm{O}_{2}$ is measured directly with the animals placed comfortably in a plexiglass capsule of about 1-1 capacity. The air $\left(\mathrm{FIO}_{2} \mathrm{O}_{2} \mathrm{2}\right)$ in each capsule is recirculated at a rate of $2 \mathrm{l} / \mathrm{min}$ through a carbon dioxide absorber and dessicant. Consumed oxygen is replaced from a Krogh spirometer filled with pure oxygen, fully saturated with water. The movement of the spirometer is recorded with a linear differential transducer and amplifier (Sanborn) and strip-chart recorded (Mosley) (Fig. 1). The system is run until stable and linear utilization of oxygen is achieved (usually within $3-5 \mathrm{~min}$ ). The time required to consume $50 \mathrm{ml}$ of oxygen is then determined and the rate of oxygen consumption calculated, correcting the volume to dry gas at standard temperature and pressure. Immediately after measurement of oxygen consumption the pulmonary artery catheter is withdrawn through the right side of the heart and pressures are recorded from the pulmonary artery, right ventricle, and right atrium. Blood samples are drawn from the systemic arteries, pulmonary artery, and right atrium for blood gas determinations, oxygen saturation, and hemoglobin concentration. Cardiac output is calculated using the Fick principle from the measured oxygen consumption and oxygen contents derived from the saturation measurements and hemoglobin concentration and normalized per kilogram body weight.

Immediately after the hemodynamic study the newborn animals were killed by an overdose of sodium pentobarbital $(300$ $\mathrm{mg} / \mathrm{kg}$ ). As soon as respiration ceased, the chest was opened and the heart and lungs removed en bloc. The pulmonary arteries were injected with a barium gelatin suspension at a pressure of $67 \mathrm{~mm} \mathrm{Hg}$ before distension-fixation with $10 \%$ buffered formalin. After fixation lung volumes were measured by water displacement and four blocks were taken, one each from the larger cranial and caudal lobes of each lung, and $4 \mu$ sections were cut and stained with hematoxylin-eosin and Miller's elastin-Van Gieson stain. Morphometric analysis of the pulmonary vasculature using light microscopy was performed according to the methods developed by Reid and colleagues $(14,15)$ that have been applied to the study of the human and animal lung in health and disease. Briefly, in each section the barium filled arteries were examined (about 70/animal), structure was recorded, wall thickness measured, and percentage of wall thickness was calculated by using the formula $(2 \times$ wall thickness $\times 100 /$ external diameter). The accompanying airway was identified as being preacinar, terminal bronchiole, respiratory bronchiole, alveolar duct, or alveolar wall. The structure of the pulmonary veins was also examined.

\section{RESULTS}

The hypoxic newborns were usually smaller and weaker and weighed substantially less than the controls (hypoxic $78 \pm 4.1 \mathrm{~g}$ : control $97 \pm 3.1 \mathrm{~g}$ ). Their hematocrits were higher than controls (hypoxic $48.9 \pm 1.1 \%$ : control $42.3 \pm 0.7 \%$ ). The arterial pHs were similar in both groups (hypoxic $7.39 \pm 0.03$; control 7.41 \pm 0.01 ) while the arterial $\mathrm{pO}_{2}$ values tended to be slightly higher in the hypoxic group (hypoxic $81.6 \pm 9.4 \mathrm{~mm} \mathrm{Hg} ; 70.0 \pm 4.8$ control).

\section{HEMODYNAMICS}

Satisfactory pressure recordings were obtained from the pulmonary and systemic arteries from each animal in both groups. For technical reasons, an accurate measurement of oxygen consumption was only available from five animals in the hypoxic group and 15 control animals and so calculation of cardiac output was possible only for these animals. Pulmonary and systemic artery pressures were similar in the hypoxic and control groups (hypoxic $26.2 \pm 1.2 \mathrm{~mm} \mathrm{Hg}$; control $23.6 \pm 0.8 \mathrm{~mm} \mathrm{Hg}$ ) (Fig. 2). Oxygen consumption was much lower in the hypoxic than control group (hypoxic $29.9 \pm 1.2 ; \mathrm{ml} / \mathrm{min} / \mathrm{kg}$; control 73.9 


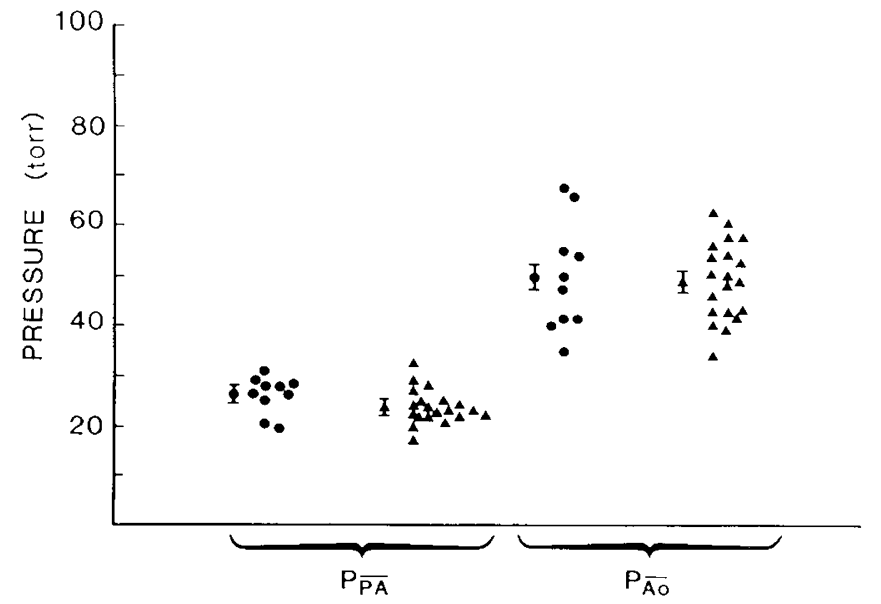

- prenatal hypoxia $(n=10)$

- room air controls $(n=20)$

Fig. 2. Pulmonary and aortic pressures in newborn guinea pigs born to sows maintained either in room air (controls) or under hypobaric conditions (prenatal hypoxia). The hypoxic and control animals are similar.

Table 1. Hemodynamic findings (mean $\pm S E M)^{*}$

\begin{tabular}{lrrcc}
\hline & PPA & PSA & $\dot{\mathrm{VO}}_{2}$ & $\mathrm{CO}$ \\
\hline Control & 23.6 & 48.9 & 73.9 & 1121 \\
$(n=15)$ & 0.8 & 1.7 & 9.5 & 134 \\
& & & & \\
Hypoxia & 22.8 & 51.1 & $29.9 \dagger$ & $413 \dagger$ \\
$(n=5)$ & 1.9 & 5.3 & 1.2 & 71 \\
\hline
\end{tabular}

* PPA, mean pulmonary artery pressure ( $\mathrm{mm} \mathrm{Hg}$ ); PSA, mean systemic artery pressure $(\mathrm{mm} \mathrm{Hg}) ; \mathrm{CO}$, cardiac output $(\mathrm{ml} / \mathrm{min} / \mathrm{kg})$.

$\dagger p<0.001$.

$\pm 9.5 \mathrm{ml} / \mathrm{min} / \mathrm{kg}$ ). Since the arterial-venous oxygen differences were similar in both groups, the calculated cardiac output of the hypoxic animals was only $37 \%$ that of the control population (hypoxic $413 \pm 71 \mathrm{ml} / \mathrm{min} / \mathrm{kg}$; control $1121 \pm 134 \mathrm{ml} / \mathrm{min} / \mathrm{kg}$ ) (Table 1).

\section{VASCULAR MORPHOMETRY}

Lung volumes were smaller in the hypoxic than control group but were normalized for body weight; they were similar in both (hypoxic $5.4 \pm 0.2 \mathrm{~mm} / 100 \mathrm{~g}$ : control $5.4 \pm 0.4 \mathrm{~mm} / 100 \mathrm{~g}$ ). By light microscopy, alveolar development appeared normal in all. From the hypoxic group, an average of 73 barium filled arteries were examined from each animal compared to an average of 71 arteries from each animal of the control group. The intraacinar arteries accompanying the respiratory bronchioles, alveolar ducts, and alveolar walls were examined for evidence of extension of muscle into peripheral arteries. In both groups, the percentage of nonmuscular arteries at each airway level was similar indicating that prenatal hypoxemia had not caused abnormal muscularization (Fig. 3). Furthermore, the normally muscular, preacinar arteries (50-500 $\mu$ in external diameter) had normal percent wall thicknesses; there was no evidence of increased medial muscle mass when related to size (Fig. 4). In the hypoxic animal the arteries accompanying the terminal and respiratory bronchioles had a smaller external diameter, meaning that smaller arteries were muscular than in controls (terminal bronchioleshypoxic $61.4 \pm 6.5$ : control $95.9 \pm 44.6 p=<0.001$; respiratory bronchioles-hypoxic $29.1 \pm 2.8$ : control $62.6 \pm 3.8$, $\mathrm{p}=<0.001$; and alveolar ducts-hypoxic $30.9 \pm 2.3$ : control $38.6 \pm 1.7, p=<0.02$ ). The perivascular collagen was similar in animals of both groups as were the veins.

\section{DISCUSSION}

Over the last 30 yr numerous studies have reported a marked pressor effect of acute hypoxia on the pulmonary vascular bed of the near term fetus and newborn. Several investigators have shown a considerably greater increase in the hypoxic response in the presence of increased hydrogen ion concentration and during asphyxia $(5,9,10)$. Such hyperractivity of the newborn pulmonary circulation has been attributed to the increased medial wall thickness of the small muscular preacinar pulmonary arteries present at this age $(16,17)$. As early as 1962 Naeye and Letts (18) described excessive muscularity of the pulmonary microcirculation of infants who remained hypoxemic after birth. Such observations prompted the speculation that chronic hypoxemia in utero increases the muscularity of the pulmonary circulation which might be responsible for the condition known as the pulmonary hypoperfusion syndrome (19), later called persistent fetal circulation (20) and persistent pulmonary hypertension of the newborn (21).

There are relatively few reports of the effects of chronic fetal hypoxemia on the function or structure of the pulmonary vasculature. In 1976 Gersony et al. (22) reported respiratory distress,

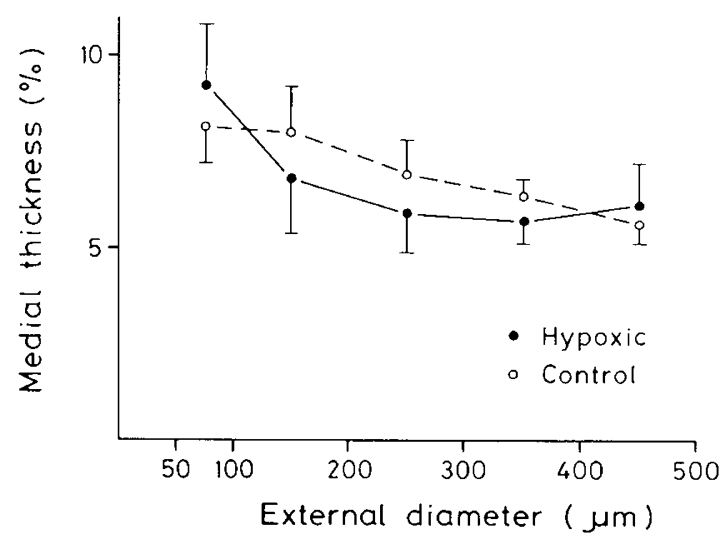

Fig. 3. Distribution at three airway levels of arteries grouped according to structre. The hypoxic and control animals are similar.
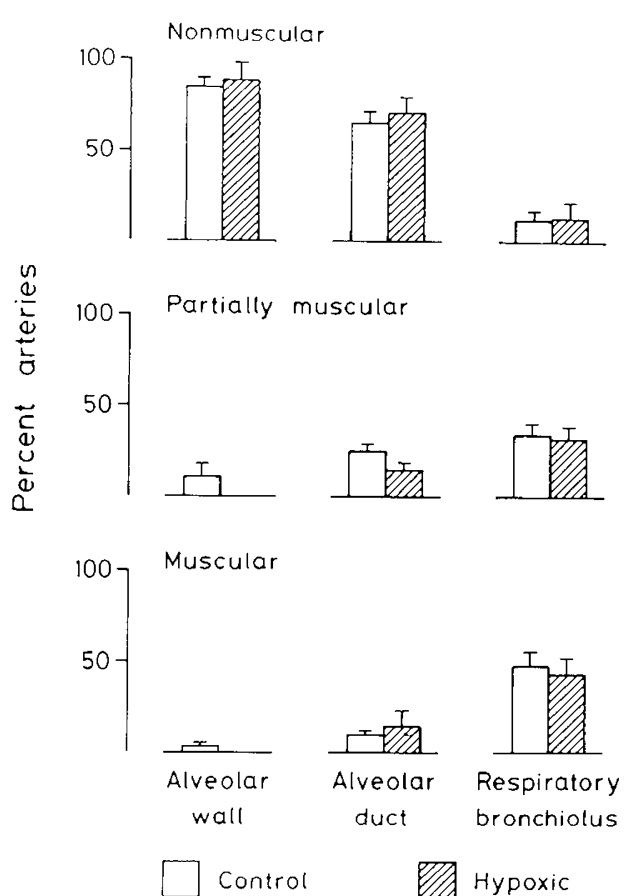

Fig. 4. Percent medial wall thickness plotted against arterial external diameter (mean \pm SEM). The hypoxic and control animals are similar. 
pulmonary hypertension, and right-to-left shunting in newborn lambs in response to hypoxemia produced by a 24 -h period of maternal hypotension. More recently, Soifer et al. (23) reported a sustained increase in pulmonary artery pressure and resistance in the lamb following prolonged compression of the umbilical cord in utero. To our knowleged the only report to date on the structure of the newborn pulmonary vasculature after chronic intra uterine hypoxemia is that of Goldberg et al. (24) who exposed pregnant rats to 13-15\% oxygen for the last half of gestation (10 days) and examined the lungs histologically. In the hypoxic group they report that the undistended small muscular arteries, $50-100 \mu$ in external diameter, had a thicker medial coat than in the controls. It is not possible to exclude constriction as the cause of this seeming increase in muscularity.

Contrary to our expectations, the chronic maternal hypoxemia did not produce pulmonary hypertension or the structural remodeling of the pulmonary vascular bed such as we found consistantly in human cases of idiopathic persistent pulmonary hypertension of the newborn. The most striking effect on the newborn guinea pig of chronic hypoxemia in utero was growth retardation, a feature not at all typical of the human syndrome. The reduction in external diameter of the arteries of the precapillay alveolar unit could be part of the general failure of growth.

The marked difference in $\dot{\mathrm{VO}}_{2}$ between the two groups raises questions regarding the metabolism of the animals in each group. The mean $\mathrm{VO}_{2}$ in the hypoxic group was only $40 \%$ of the control group, but within the range measured in older guinea pigs using the same apparatus. One explanation for the difference is that although throughout the hemodynamic studies the animals were maintained under radiant warmers, they may not have been in a neutral thermal environment. In a recent study newborn lambs were found to increase their $\dot{\mathrm{VO}}_{2}$ by $40 \%$ without shivering when placed in a cool enviornment $\left(17^{\circ} \mathrm{C}\right)(25)$. It is plausible that in a relatively cool environment the control animals were able to raise $\dot{\mathrm{VO}}_{2}$ and cardiac output appropriately, while the smaller, growth-retarded hypoxic animals were not.

We expected, based on the earlier studies, that the newborn guinea pigs exposed to intrauterine hypoxemia would have pulmonary hypertension and structural changes in the microcirculation of the lung but neither occurred. While it has been shown that the fetal lamb responds to maternal hypoxia with a considerable decrease in $\mathrm{PO}_{2}(26)$, there is little information concerning smaller animals. From previous studies in our laboratories we know that young and adult guinea pigs respond to chronic alveolar hypoxia by developing pulmonary hypertension like most other animals. It seems unlikely, therefore, that the absence of structural vascular change in utero represents a species peculiarity.

\section{REFERENCES}

1. Fishman AP 1961 Respiratory gases in the regulation of the pulmonary circulation. Physiol Rev 14:214-280
2. James LS, Rowe RD 1956 The pattern of response of pulmonary and systemic arterial pressures in newborn and older infants to short periods of hypoxia J Pediatr 51:5-11

3. Lloyd TC Jr 1964 Effect of alveolar hypoxia on pulmonary vascular resistance. J Appl Physiol 19:1086-1094

4. Lloyd TC Jr 1966 Influence of blood $\mathrm{pH}$ on hypoxic pulmonary vasoconstriction. J Appl Physiol 21:358-364

5. Rudolph AM, Yuan S 1966 Response of the pulmonary vasculature to hypoxia and $\mathrm{H}+$ ion concentration changes. $\mathrm{J}$ Clin Invest 45:399-411

6. Meyrick B, Reid L 1978 The effect of continued hypoxia on rat pulmonary arterial circulation. Lab Invest 38:188-120

7. Rabinovitch M, Gamble W, Nadas AS, Miettinen OS, Reid L 1979 Rat pulmonary circulation after chronic hypoxia: hemodynamic and structural features. Am J Physiol 236:H818-H827

8. Rabinovitch M, Gamble W, Miettinen OS, Reid L 1981 Age and sex influence on pulmonary hypertension of chronic hypoxia and on recovery. Am $\mathrm{J}$ Physiol 240:H62-H72

9. Campbell AGM, Cockburn F, Dawes GS, Milligan JE 1967 Pulmonary vasoconstriction in asphyxia during cross circulation between twin fetal lambs. $J$ Physiol 192:111-121

10. Campbell AGM, Dawes GS, Fishman AP, Hyman Al 1967 Pulmonary vasoconstriction and changes in heart rate during asphyxia in immature fetal lambs. J Physiol 192:93-110

11. Murphy JD, Rabinovitch M, Goldstein JD, Reid LM 1981 The structural basis of persistent pulmonary hypertension of the newborn infant. $J$ Pediatr 98:962-967

12. Murphy JD, Vawter GV, Reid LM 1984 Pulmonary vascular disease in fatal meconium aspiration J Pediatr 104:758-762

13. Herget J, Palacek F 1972 Pulmonary artery blood pressure in closed chest rats, changes after catacholamines, histamine and serotonin. Arch Int Pharmacodyn 198:107-117

14. Hislop A, Reid L 1974 Arterial changes in Crotalaria spectabilis induced pulmonary hypertension in rats. Br J Exp Pathol 55:153-163

15. Hislop A, Reid L 1976 New findings in pulmonary arteries of rats with hypoxia induced pulmonary hypertension. Br J Exp Pathol 57:542-554

16. Hislop A, Reid L 1972 Intrapulmonary arterial development during fetal life-branching pattern and structure. J Anat 113:35-48

17. Wagenvoort CA Neufeld HN, Edwards JE 1961 The structure of the pulmonary arterial tree in fetal and early postnatal life. Lab Invest 10:751-762

18. Naeye RL, Letts HW 1962 The effects of prolonged neonatal hypoxemia on the pulmonary vascular bed and heart. Pediatrics 30:902-908

19. Chu J, Clements JA, Cotton E, Klaus MH, Sweet AY, Thomas MA, Tooley WH 1965 The pulmonary hypoperfusion syndrome. Pediatrics 35:733-742.

20. Gersony WM, Duc GV, Sinclair JC 1969 "PFC syndrome" (persistent fetal circulation). Circulation 40:1II-87 (abstr)

21. Levin DL, Heymann MA, Kitterman J, Gregory GA, Phibbs RNM, Rudolph AM 1976 Persistent pulmonary hypertension of the newborn infant. J Pediatr 89:626-630

22. Gersony WM, Morishima HO, Daniel SS, Kohl S, Cohn H, Brown W, James LS 1976 The hemodynamic effects of intrauterine hypoxia: an experimental model in newborn lambs. J Pediatr 89:631-635

23. Soifer SJ, Kaslow D, Heymann MA 1983 Prolonged intrauterine hypoxia produces pulmonary hypertension in the newborn lamb. Pediatr Res $17: 336 \mathrm{~A}$

24. Goldberg SJ, Levy RA, Siassi B, Betten J 1971 The effects of maternal hypoxia and hyperoxia upon the neonatal pulmonary vasculature. Pediatrics 48:528533

25. Sidi D, Kuipers RG, Heymann MA, Rudolph AM 1983 Effects of ambient temperatures on oxygen consumption and the circulation in newborn lambs at rest and during hypoxemia. Pediatr Res 17:254-258

26. Parker HR, Purves MJ 1967 Some effects of maternal hyperoxia and hypoxia on the blood gas tension and vascular pressures in the fetal sheep. Q $J$ Exp Physiol 12:205-221 